\title{
The Opportunity of Applying Digital Currency in SEKEM community Egypt
}

\author{
Aly Saad Mohamed Dawood ${ }^{1}$, Sherif Emad El-kabany ${ }^{2}$ \\ ${ }^{1}$ Associate Professor of Business Administration Sadat Academy for Management Sciences Seconded to Heliopolis University for \\ Sustainable Development Faculty of Business and Economics \\ ${ }^{2}$ Bachelor's of Finance and Investment
}

\begin{abstract}
This paper examines the opportunity of applying digital currency in a sustainable community called SEKEM, where SEKEM is always encouraging innovation practices that focus on developing their community in a sustainable way.

A framework has been suggested by utilizing readymade SEKEM MIZA extracted from Cyclos 4 system after redesign according to proposal framework targets, then making initial survey to measure questionnaire reliability which exceed 0.8 .

A descriptive research methodology utilized to identify the success opportunity of applying such framework in SEKEM community by questionnaire survey designed for such purpose on a convenient sample of 114 respondents.

It was found that applying digital currency in such community will lead to explore opportunities to reduce the cost of living and education for community respondents and also add value to SEKEM as a special business pattern.
\end{abstract}

KEYWORDS: Digital Current; Sustainable community; Egypt.

\section{INTRODUCTION}

\subsection{Overview}

In ancient times goods and services were exchanged for goods and services until payment were being introduced in the form of some currency. Now a day Paper Currency is country-wide accepted common medium of trade. Every country has its own paper currency exchangeable by other currencies of the world at an arbitrary rate (J.W.Biggs, 2018). There are three main function of the paper currency as it used as a medium of exchange, being a numerical unit for the measurement of goods and services value, and as a store of value which could be used in the future. Most innovations now a day is moving toward digital forms to reduce the waste of time and be more efficient. The idea of merging between the traditional features of money and the modern electronic transactions is known in the financial world as Digital currency, it is a new medium source of exchange that is based on internet to allow quick transactions (Shah, 2017). These currencies could be used to buy various products and services on the digital platform. The digital currency requires a computer or cell phone connected with Internet, and moderate educated person after short training can make transactions on it. The adoptability of digital currency will be faster in advanced countries and slower in developing countries due to the low literacy rate and lacking of information technology infrastructure (Kaplanov, 2012). There are a lot of digital currency types, but the most common published type is virtual-crypto currency, as the Bitcoin was the first successful example of digital currency under the type of virtual crypto currency (Bryans, 2014).

Forming a digital currency platform start first by creating an exchange circle that offer their participants the opportunity to offer and exchange their goods and services with each other without using national currencies as a medium of exchange (Shah, 2017). Investing in digital currency requires first to exchange from national currency into digital currency, so you can have the access to buy or sell products or services inside the circle using this digital currency for trading.

Since 2016 and after the sustainable development goals were introduced by the United Nations, a lot of business companies changed their practices into sustainable development practices, to mobilize efforts to help the community and ensure that no one is left behind. From here came the idea of the paper, which is mixing between the innovation of the digital currency and the sustainable development practices to describe the opportunity of applying digital currency in SEKEM community (JianiWu, Nguyen Khoi Tran, 2018).

\subsection{Research Importance}

The importance of the research is that it forms a clear overview about the opportunity of applying digital currency in SEKEM community, clarifying the benefits of applying digital currency on SEKEM community and its members from different entities, and supporting SEKEM with a smart conceptual framework. 


\section{"The Opportunity of Applying Digital Currency in SEKEM community Egypt"}

\subsection{Research Objective}

The objective of the research is to describe the opportunity of applying digital currency in SEKEM community and to support SEKEM with a smart conceptual framework of applying digital currency that will add value to their sustainable community.

\section{LITERATURE REVIEW}

\subsection{Digital currency}

Using goods as a general equivalent was the basic form of monetary value. Historically, with the development of the global trade, gold was the world common currency. In 1972, the dollar withdraws the function of the world currency from gold as a result of the government's efforts. The expansion of the internet was playing an important role in reducing the paper currency circulation, by creating a mix of innovative opportunity between the financial sector and technological sector, forming new field called financial technology (FinTech). Now a day's paper currency transactions start to disappear gradually as result of introducing the digital currency in the financial sector (Jian, 2020).

Representing financial values in digital format became globally known as digital currency (J.W.Biggs, 2018). A new medium of exchange that is more innovative, with fast and easy transactions, and differs from the traditional exchange was available via digital means (Shah, 2017). A short training on a mobile phone or computer connected to the internet would be the first step for any person would like to make transactions using digital currency app or program.

The greater information technology infrastructure would cause a faster ability to use digital currency. Both official and conventional digital currencies are two main sides that must be mentioned in presenting digital currency, as each side is completely different and requires different system in implementing it. The official digital currency system is issued and generated by a central bank or government. As a result it could be exchanged by the country paper currency as it is issued by the same government.

There are no enough scientific papers about any official digital currency controlled and issued by government, but there are relevant concepts related to this topic. The conventional digital currency system is unregulated digital money as it is issued and controlled by its developers, and it is accepted by a group of members whom use it in a trade circuit. (Shoaib, M., Ilyas, M., \& Khiyal, M. S. H., 2013). Now conventional currency is not only limited to online games, but also it is used with real goods and services.

\subsection{Successful Digital Currency}

In 2008, Satoshi Nakamoto a Japanese researcher wrote a scientific paper called "Bitcoin with a view to discussing cryptography". The paper was spotting on how to group several different past inventions to implement decentralized payment system known as virtual crypto currency. Bitcoin was introduced to the financial market in 2009 , as the fast secured payment system in the form of virtual crypto currency. What was new regarding the system of Bitcoin is that it was functioning without an intermediary channel or authority. Within the Bitcoin network, financial products and services and also the other currencies could be transacted as a digitalized financial system. In 2010, after the Bitcoin was presented and verified in the blockchain technology, it was the highest value for global trading (Kaplanov, 2012).

As previously mentioned Bitcoin transactions occur directly between clients and are entered into a central database known as a ledger, which means that there is no banking intermediary acting as a central server between users. 21 million Bitcoin is published and this is the total number of Bitcoin available in the market. Since 2011 and until 2021 the Bitcoin price had increased from almost $0 \$$ to $60,000 \$$ and the price will still fluctuates as it depends mainly on the demand of Bitcoin. Is Bitcoin a currency or an investment asset? People always ask this question about the Bitcoin. (Chen, Pandey , 2014) Tested Bitcoin as a currency, they found that there is a correlation between all the world currencies and each other, but there is no correlation between Bitcoin and the world currencies. (Briere, M., Oosterlinck, K., \& Szafarz, A, 2013) Analyzed Bitcoin as an investment asset, they found that Bitcoin has a higher average return, it is more volatile asset, and with other assets it has low correlation. As a result, Bitcoin is more useful as an asset investment, but it is an innovative digital currency. Bitcoin is not the only successful virtual crypto currency that exists, there is another currency called Litecoin, which is a peer-topeer, open-source, and decentralized virtual crypto currency. Litecoin is launched in 2011 with a total number of 84 million Litecoin, which is four times the total amount of Bitcoin. Also Litecoin is less volatile, as the price goes up smoothly depending on the demand (Houben, R., \& Snyers, A., 2018).

\subsection{Islamic Prospective}

The Islamic financial technological system is not accepting any activities that contain ambiguity, gambling, and interest. The Islamic financial industry is focusing to prevent these three elements in any financial transaction, and this is how the Islamic financial system is different from the conventional financial system (Ibrahim Bassam Zubaidi,Adam Abdullah, 2017). Money is considered as a measurement of economic value and as a medium of exchange, so getting a return from using money without doing a productive activity is totally rejected from the Islamic point of view (Omar, 2011).

The development of a secure and transparent payment system is the advantage of digital currency, as it is going to be available for the unbanked individuals in an efficient way causing more people to be included in the financial and economic activities. (Singhal, A., \& Rafiuddin, A, 2014) Discussed that digital currency could be a well suited alternative of the paper currency, but it needs to be controlled in a sufficient way. The Islamic financial system is accepting the digital currency innovation, if it is going to seek solutions toward helping the community, and forming social objectives 


\section{"The Opportunity of Applying Digital Currency in SEKEM community Egypt"}

within the Islamic function of money (Ibrahim Bassam Zubaidi,Adam Abdullah, 2017).

\subsection{Complementary Currency}

People often become smart in order to make sure of the survival of themselves, their family, and their environment in the times of crisis. A lot of secondary exchange methods and digital currencies which differ from the legal tender were developed since 1931 and until now, focusing on stimulating the market into more sustainable way (Michel, 2015). Complementary currency, which is globally know as a monetary tool or trade system, issued and used by governments, communities, individuals, and groups in order to make it easy to trade goods and services. As a result a significant amount of users across all sectors would be required to circulate complementary currency as all sectors well depend on each other to create more sustainable society. The basic need of the complementary currency is to be always complementing the original country currency in terms of the political, economic, and social aspects. The complementary currency is not only promoted as a source of economic benefit, but also it may aim to make profit. Ora a complementary currency that is located in South Africa established in 2004 were a group of users were trading goods and services with a physical complementary currency called Ora. Currently the Ora is updated to e-Ora digital platform, which will reduce the direct replacement of the physical Ora complementary currency (Francisco Javier García-Corral, 2020).

\subsection{Energy Currency}

As the human beings use of energy is limited and insufficient, and as the free energy is infinite and can be transformed into social system, therefore the free energy is more useful to human beings. All the valuable things were acting as general equivalents, and using goods as general equivalents was the original structure of the monetary value. Gold as an example became the world currency with the spreading out of the trade scope (Jian, 2020).

The digital payment system became published slowly, and the use of the paper money gradually reduced with the development of internet. As energy is the source of value, it could be the ideal currency to describe the intention force of development. The natural digital currency based on block chain technology is called energy currency. Energy currency can be used as a standard currency for measuring values, as it can be transformed into real value and also as it is a natural decentralized digital currency. The digital energy currency system can avoid inflation and deflation, as it can control the amount of money according to the size of the market goods and services (JianiWu, Nguyen Khoi Tran, 2018).

Historically, the financial sectors were suffering from various currency problems like no value base for digital currency, inflation of legal currency, and the gold deflation. As energy currency is developing a new global economic world with more efficient and fare trade, this mean that energy currency can be the future digital global currency.

\subsection{Virtual Crypto Currency}

One of the most know digital currencies sub-set that is developed in a cryptographic digital exchange system that manage the creation of a new digital currency, securing transaction and form an easy transfer, is known as virtual crypto currency (Aytaç Altan, Seçkin Karasu, Stelios Bekiros, 2019). Through the virtual crypto currency, users could make exchange, transaction, and transfer without having the central bank of the country as a medium of exchange.

Decentralizing virtual crypto currency has several advantages, as there will be no medium of exchange the probability of hacking and compromising the data would be lower than the traditional currency which means more safety (Bryans, 2014). Also the people that are suffering from the restrictions and polices of the national banks, could use the virtual crypto currency as an alternative. The virtual crypto currency is defined by the European Central Bank as a digital value exchange system that is not issued by a central bank and could be used as an alternative of the legal paper currency. There is a lot of similarity between crypto currency and precious metal, as we know that precious metal allows the inflation protection to eliminate legal money, and crypto currency also follows the process to exist in the global market. There is a common feature between virtual crypto currency and valuable metal that were used by the virtual crypto currency to exist in the global financial market, which is that both of them allow inflation protection to get rid of legal paper currency (Hossain, 2021).

The virtual crypto currency exists in the market with two main types, the first type is found in the online gaming programs known as nonconvertible digital currency as it can't be converted into legal paper currency. The second type is found in the exchanging system known as convertible digital currency as it can be converted into legal paper currency (FATF, 2014). As previously mentioned, Now a day there are some companies are accepting digital currency payment without the need of a medium of exchange, Travala as an example which offers bookings for hotels, accept most crypto currencies, as a result the virtual crypto currency is more used as an alternative for the legal paper currency as it is faster. The virtual crypto currency could be issued by any individual or institution, and the exchange price of the virtual crypto currency could be the same as the legal paper currency or could be different depending on the supply and demand of the market (Xu, 2020). The exchange process of the virtual crypto currency occurs mainly on mobile applications where the users could sell, buy, or exchange the virtual crypto currency into legal paper currency such as US dollars or Egyptian pounds. Virtual crypto currency is a good step for existing financial technology, as it plays an important role in solving the problems of the traditional financial systems. Also 


\section{"The Opportunity of Applying Digital Currency in SEKEM community Egypt"}

it increases the international B2B transactions (Valery Titov, 2021).

\subsection{Risks of Digital Currency}

Even after the innovation of the digital currency that opened for companies and individuals more options to invest and make profit, still there are some of the world population that are not trusting digital currency as a payment method. The regulation and laws of digital currency are still not clear in many countries. The European government for example does not have a specific regulations and laws for digital currency, as they are against the digital currency activities due to its high level of risk. As previously mentioned that still there is no global specific regulation and laws regarding digital currency, criminals used this opportunity for doing illegal activities such as drug trade, money laundering, and weapons sales (Scott Gilbert, Hio Loi, 2018).

In the past, the old style of selling drugs was that a person must meet a buyer to give them what they need. Now there is something called dark web were the online drug market is located, and the buyer could easily exchange their paper currency into digital currency to make a drug transaction online without the need of the physical meeting (Groysman, 2018). Drugs dealers used digital currency to make the transactions in an easy way with low risk and more efficient than offline trading.

Since the early 1970s, the financial sector is suffering from an illegal activity done by using financial institutions called money laundering. The financial transfer had changed when the digital currency inter the financial sector, also the criminals developed a new and innovative money laundry schemes (Böhme, Christin, Edelman, and Moore, 2015). The criminals were hiding their illegal money in digital currencies as the digital currency can be purchased by paper money, so now the illegal money is replaced by digital currency. As a result, 2.8 billion dollars were exchanged by Bitcoin in 2019 . The website that cannot be found by a traditional search engine, and can only be seen through a specific browser is known as dark web. Silk Road is the best-known digital currency dark web, owned by Ross William Ulbricht, which was used to help their customer to sell a huge quantity of drugs by using digital currency. In less than two years trade volume increased very fast and Silk Road made more than 1 million dollars as revenue, from offering different kinds of drugs and serving thousands of drug dealers (Groysman, 2018).

\subsection{Financial Technology Innovation}

The financial industry is always in update due to the diversified technological innovations, the successful and innovative turning point in the financial industry is known as financial technology (Fin-tech), as it is developing fast through the global sharing economy and information technology. Fin-tech is transforming the financial industry by creating stable financial background, developing high quality financial services, and reducing costs. Consumers are getting more into the Fin-tech payment methods as it covers the entire scope of goods and services provided by financial institutions, which is making the Fin-tech faster and efficient (Rosenbaum, 2020).

The Fin-tech was defined as goods or services in nonfinancial institutions created on highly innovative and disruptive service technologies. Ernst and Young defined Fin-tech as an innovation in financial services with technology as the key enabler. Lee described Fin-tech as a type of business using hardware and software technologies to provide financial services. Consequently, Fin-tech might improve the performance of financial services and expand financial services to mobile environments (Ryu, 2018).

Currently, the Fin-tech is not only digitalizing the traditional financial services, but also it is a changing point in the financial industry, as it is focusing to meet the consumer financial needs by developing a fast innovative technological services that will satisfy the consumer needs. These technological innovations are able to control the traditional business models to maintain growth, reduce risk, and increase efficiency.

\subsection{Egypt Financial Technology Ecosystem}

Ecosystem assessment, Fin-tech vision and strategy expansion, and preparation of the road map design are the three stages to develop Fin-tech strategy in Egypt. A local and international market review in terms of demand, regulation, governance, and funding were included in the first stage which is the ecosystem assessment. Based on the key outcomes of the ecosystem assessment, the team developed the FinTech Vision and Strategy which was "a regionally recognized FinTech hub in the Arab world and Africa, home to next generation financial services, talent and innovation development". Following the approval of the Strategy, the team designed a detailed Implementation Roadmap, comprising 32 strategic initiatives to execute the Strategy and achieve the desired future state. Implementation of the FinTech Strategy started in the second half of 2019 with critical initiatives targeted for completion by the first half of 2021 (CBE, 2019).

\subsection{Summary}

The expansion of the internet was playing an important role in creating a mix of innovative opportunity between the financial sector and technological sector, forming new field called financial technology. A new medium of exchange that is more innovative, with fast and easy transactions, and differs from the traditional exchange was available via digital means. Digital currencies have two main sides which is the conventional and official digital currency. Bitcoin which was available in the financial market since 2009 was known as one of the most successful virtual crypto currencies in world, due to the high demand.

From the Islamic prospective, the digital currency innovation is accepted if it is going to seek solutions toward helping the community, and forming social objectives within the Islamic 
function of money. Regarding the three sides of risks on digital currency, it could be handled in case of applying digital currency in SEKEM community, as the individuals will convert their paper currency into digital currency with the same rate just to have the ability to get benefits such as points, so this will reduce the risks of applying digital currency.

After discussing the three types of the digital currency (crypto virtual, Energy, Complementary), the virtual crypto currency would be the most one to be applied in a community as it is developed in a cryptographic digital exchange system, and as it does not need a medium of exchange like banks. As Egypt Central Bank is implementing a strategy to develop the FinTech in Egypt, this increased the chance of applying digital currency in SEKEM community.

\subsection{Research Gap}

This research depend on building circuit suitable to SEKEM community for utilizing digital currency to reduce the cost of living inside special community, where The previous researchers were concentrating on having a well running online digital currency that enables the users to make profits. Also the previous researches do concentrate on the opportunity of having digital currency for a well-known company just to benefit from utilizing such financial technology innovation.

\section{RESEARCH CONTRIBUTION}

\subsection{Research Question}

To what extent we can apply digital proposed circuit inside SEKEM community to lower some of the living cost?

\subsection{Research Hypotheses}

- The proposed circuit by using digital currency could be applied in SEKEM community

- The circuit utilizing digital currency could lower some of living cost.

\subsection{Conceptual Framework}

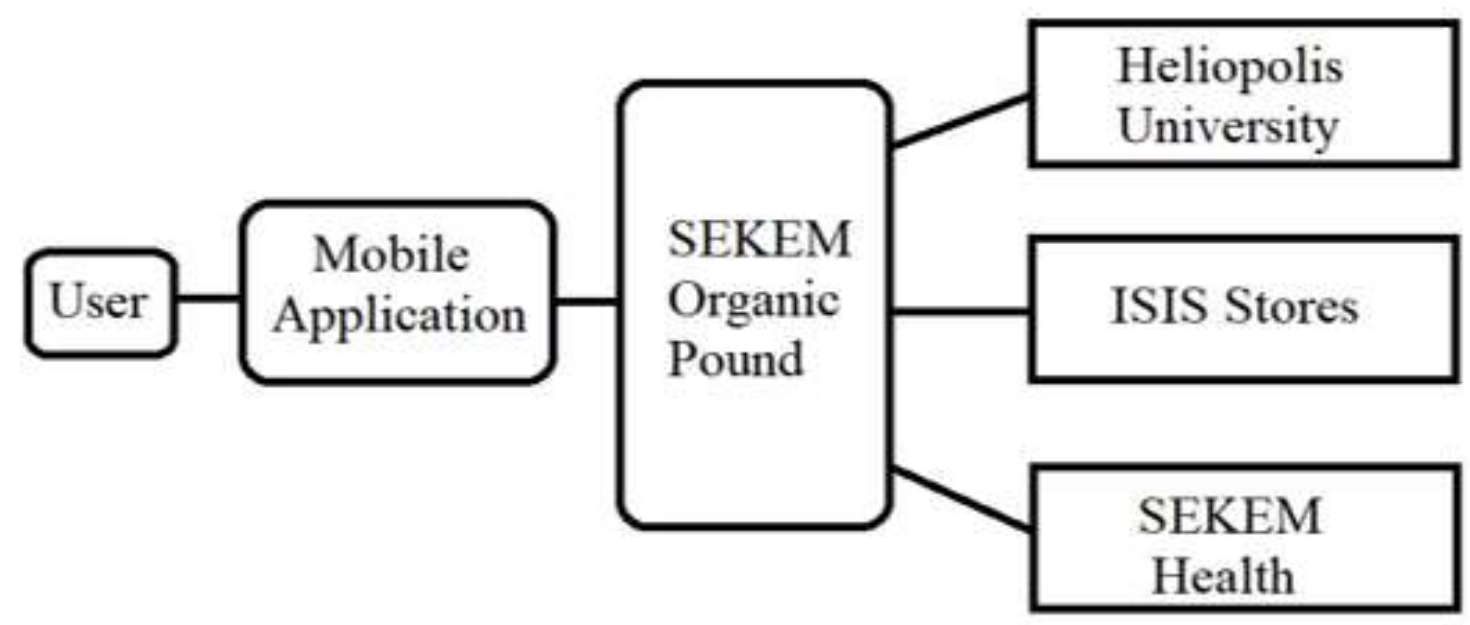

Figure (1) Conceptual Framework

The digital currency could be applied in SEKEM community in the form of mobile application that includes a digital currency called SOP (SEKEM Organic Pound). The user of this application would be required to create account, and the process of creating such account would be done in two steps. The first step is the personal information data which will require name, personal ID, data of birth, marital status, and the user role in SEKEM community which can be Student, Employees, or university staff. The second step would be the payment method where the user would be required to link a bank account with the application. The rate of the SOP would be equal to the rate of the Egyptian bounds, which mean one EGP will equal one SOP, but what is different is that when a user makes any transaction with the SOP they will gain $1 \%$ of the total transaction in terms of SOP points, where they can use it later in any other transaction to reduce the total amount of the transactions. Now the user will be able to convert their money to SOP where they can gain points, and make fast transactions inside SEKEM community. The SOP digital currency will not only make the transaction easier and faster for SEKEM community, but also the demand on SEKEM products will increase as more people will use the application to gain points which is win-win situation.

\section{Student}

Heliopolis University students could use SOP digital currency to pay their fees which will make them gain points that can be used in paying the next year university fees, purchase from ISI Cafeteria, ISIS store or SEKEM Ecohealth.

\section{Employee \& University Staff}

The employees and doctors of SEKEM community would be able to use the SOP digital currency application as wallet that make them make fast and more easier transaction inside SEKEM community and at the same time gain extra points that can be used inside SEKEM community. 


\section{RESEARCH METHODOLOGY}

\subsection{Research Approach}

As this research is describing the opportunity of applying digital currency in SEKEM community located in Egypt, a survey (questionnaire) was made on 114 respondents from holding companies and Heliopolis University to find the availability of applying digital currency in such community, and how to adjust the digital currency innovation in supporting the development of SEKEM.

\subsection{Population \& Sample \\ SEKEM}

In 1977, SEKEM was established by Prof Ibrahim Abouleish; on 200 hectares of desert land by applying biodynamic principles which is farming methods include avoiding chemical soil fertilizers to enhance soil fertility, consideration of biological organisms. The name SEKEM means according to an ancient Egyptian hieroglyph "Vitality of the Sun". SEKEM was founded with the idea of sustainable development and giving back to the community. The Entrepreneur and his helpers started against all odds to revitalize the desert soil by using Biodynamic agricultural methods and succeeded in cultivating herbs, fruits, vegetables, cotton and other crops. Due to the holistic approach of Prof Abouleish vision, SEKEM obligated itself to serve the society and established several institutions under the umbrella of SEKEM to continue processing the crops.

\section{ISIS}

In 1997, ISIS Organic was established by producing food that is wholesome, nutritious and delicious, from carefully selected raw materials that are free of any artificial additives or preservatives. The foodstuff processed and packed by ISIS Organic includes organically grown vegetables, honey, dates, herbs, spices, edible oils, and beverages such as herbal tea and juice. Following the principles of transparency, ISIS strives for honest and fair collaboration throughout the entire supply chain. Their prices for raw materials are set according to Fairtrade principles and assure a fair distribution of the value generation to their suppliers. They foster long-term relations with their suppliers through guaranteeing purchase of certain amounts of raw material and helping to pre-finance the cultivation.

\section{Nature Tex}

NatureTex was founded in 1998, originally under the name of Cony Tex. NatureTex is a high quality producer of colorful baby and kids wear, dolls and toys, home textiles, fabrics and assorted adults items using only organic cotton. The design and development of the products is done in-house in its own studio, and produced and marketed under its own brand. NatureTex competes successfully in the global market for organically produced textiles through the design, manufacturing, and marketing of beautiful and high quality products from Egypt, the home of today's premium cotton production.

\section{ATOS}

In 1986, ATOS Pharma was founded by manufactures and markets an array of natural medicines and health care products of superior quality for effective causal treatment combined with maximum tolerability. The products are developed for different indications. ATOS Pharma markets and distributes its products nationally and internationally. ATOS Pharma is committed to a regional leadership position in the field of phyto-pharmaceuticals. Its foremost goal is to promote the extreme benefits of natural medicine in the region.

\section{Heliopolis University for sustainable development}

In 2009, Prof. Abouleish established Heliopolis University for Sustainable Development which is the first university in the Middle East declaring sustainable development as its main guiding principal. Heliopolis University for Sustainable Development was inaugurated in 2012 with the aim to open up the introduction of the concepts and principles of sustainable development to its students and to the Egyptian community at large. Currently Heliopolis University for Sustainable Development includes the faculties of Engineering, Pharmacy, Business and Economics, Physical Therapy, and Organic Agriculture. The degree programs offered at Heliopolis University address the concepts and theories of sustainable development through a multi-disciplinary holistic approach that integrates teaching, learning, research, and practice. In addition, all students participate in the cross-faculty Core Program which presents arts, music, theater, languages and much more, striving to open creativity and innovation. The program further enriches the learning experience by focusing on sustainability and human development.

\subsection{Data Collection}

In May 2021, a survey on convenient sample of SEKEM holding companies and Heliopolis University staff was prepared to describe the ability of applying digital currency in SEKEM community; the total sample size was 114, with $64 \%$ males and $36 \%$ females, different ages between 18 to 53 years old. The sample level of education with percentage is $76 \%$ undergraduate, $15 \%$ with bachelor degree, $5 \%$ with master degree, $3 \%$ PHD, $1 \%$ diploma. The sample occupation with percentage is $74 \%$ students, $19 \%$ employees, $7 \%$ professors \& doctors.

\subsection{Data Reliability}

Table (1) Reliability test

/Variables= DV1.1 DV1.2 DV1.3 DV1.4

/Model=Alpha

\begin{tabular}{|l|l|l|}
\hline Cases & $\mathrm{N}$ & Percent \\
\hline Valid & 113 & $99 \%$ \\
Excluded & 1 & $1 \%$ \\
Total & 114 & $100 \%$ \\
\hline Cronbach's Alpha & N of Items \\
\hline 0.87 & 4 \\
\hline
\end{tabular}

Source: SPSS 
The previous table showed that the data is reliable where Cronbach's Alpha is 0.87 .

\subsection{Survey results}

The following graphs show the respondents answers on questionnaire:

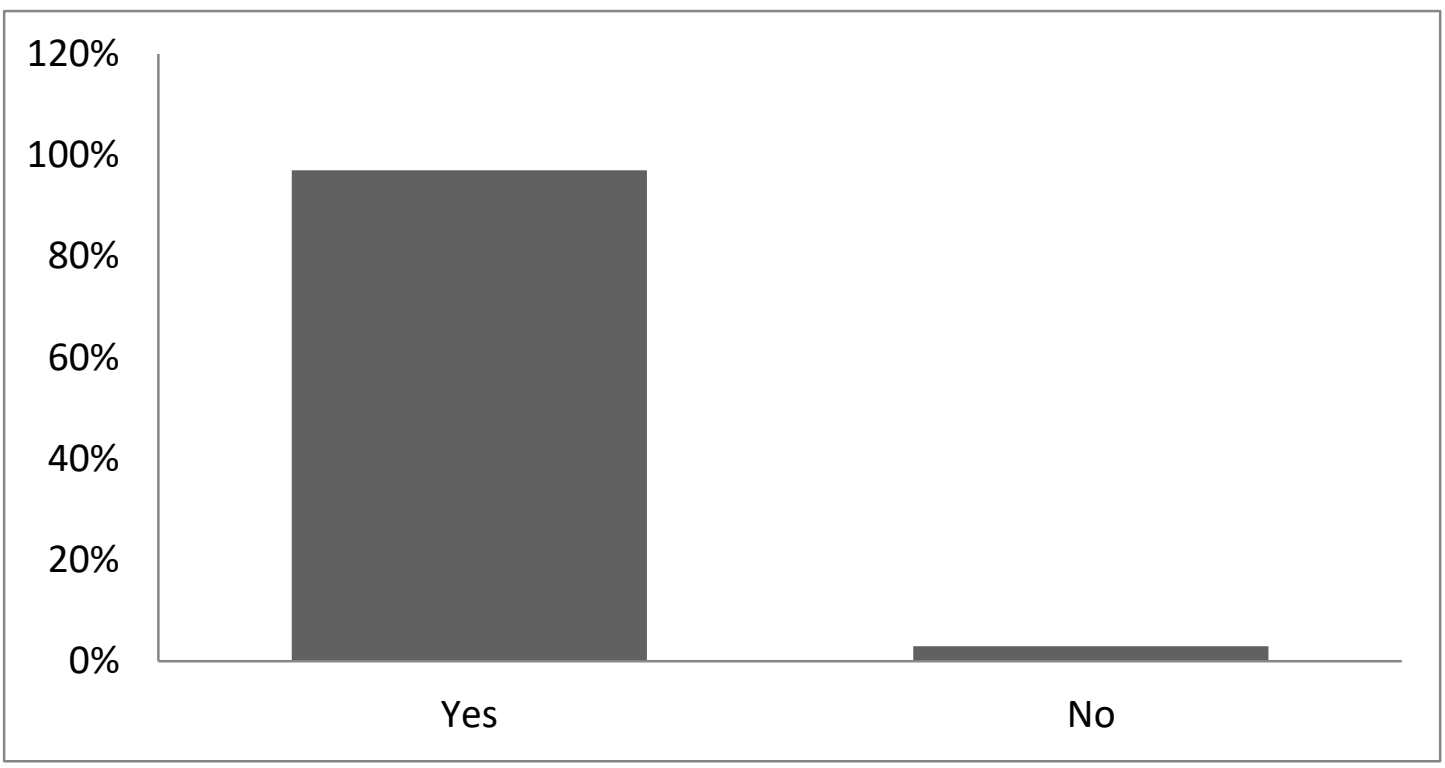

Figure (2) I have smart phone

$97 \%$ have a smart phone, which indicates that most community respondents own the needed peripheral to apply the suggested framework.

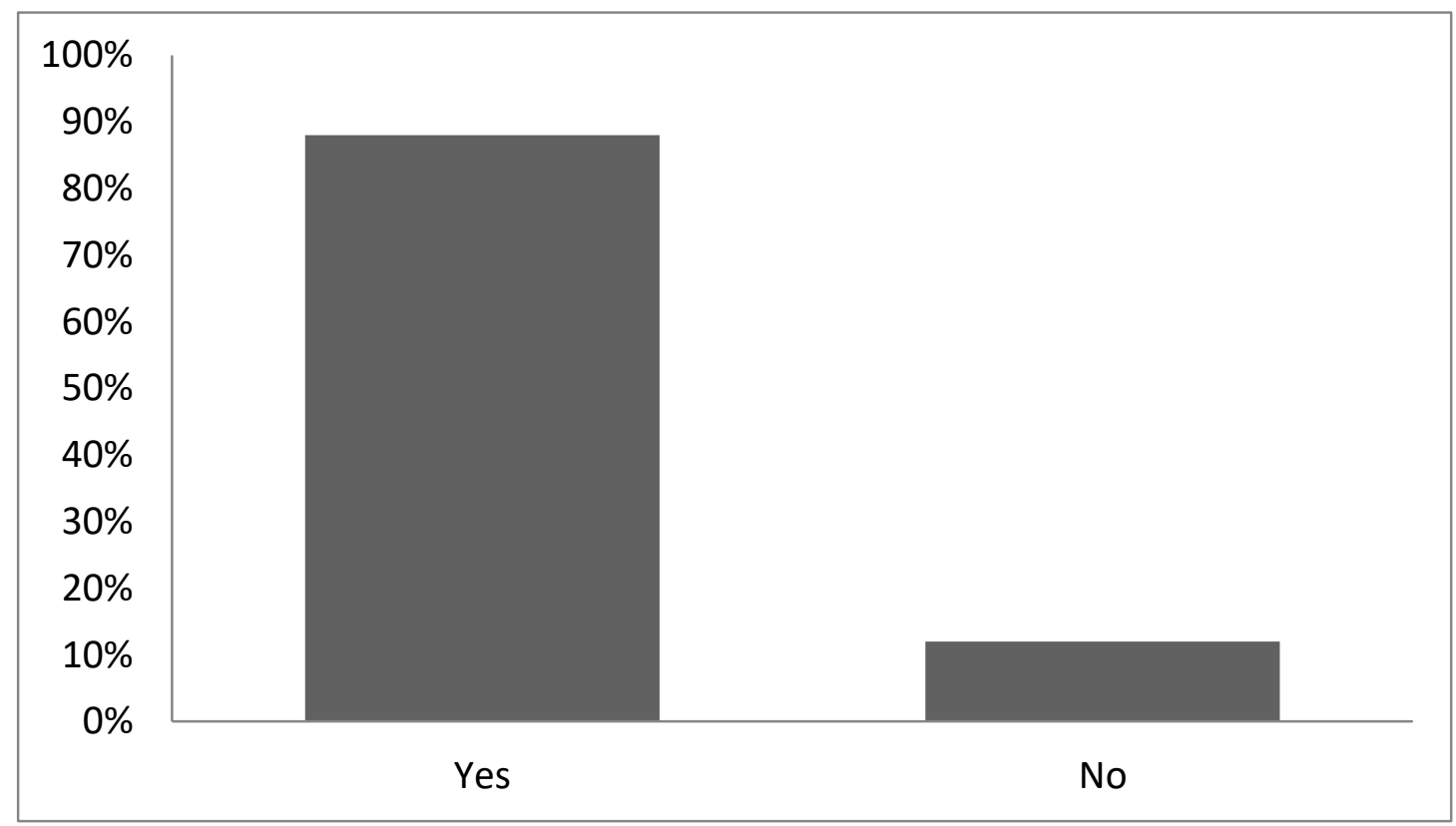

Figure (3) I am an active member on social media platforms

$88 \%$ are active members on social media, which indicates that that most community respondents are using digital application that requires internet. 


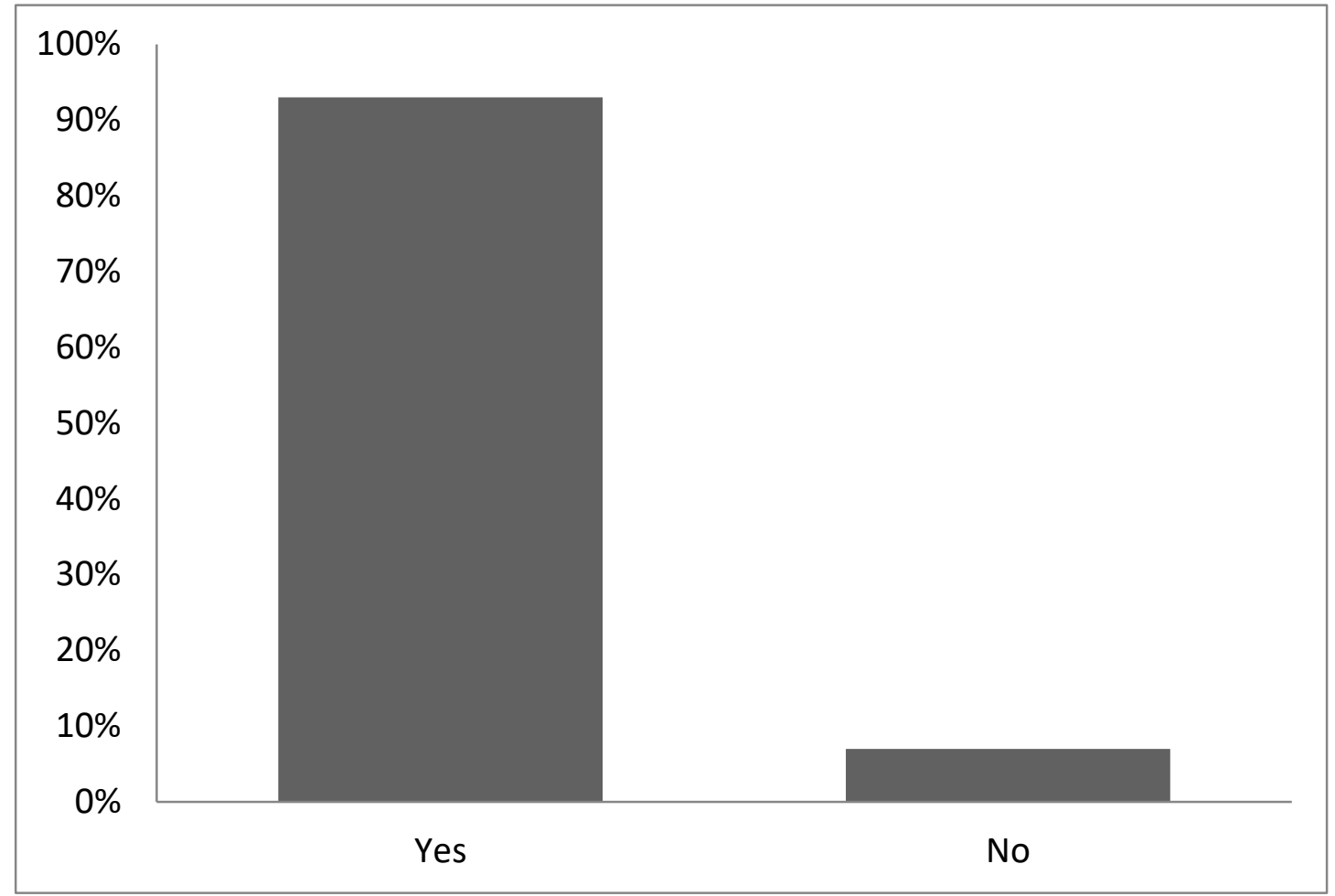

Figure (4) I heard about digital payment application

93\% are using digital payment application, which indicates that respondents are accepting the idea of the digital payment.

Figure (4) I am using one of the following digital payments applications

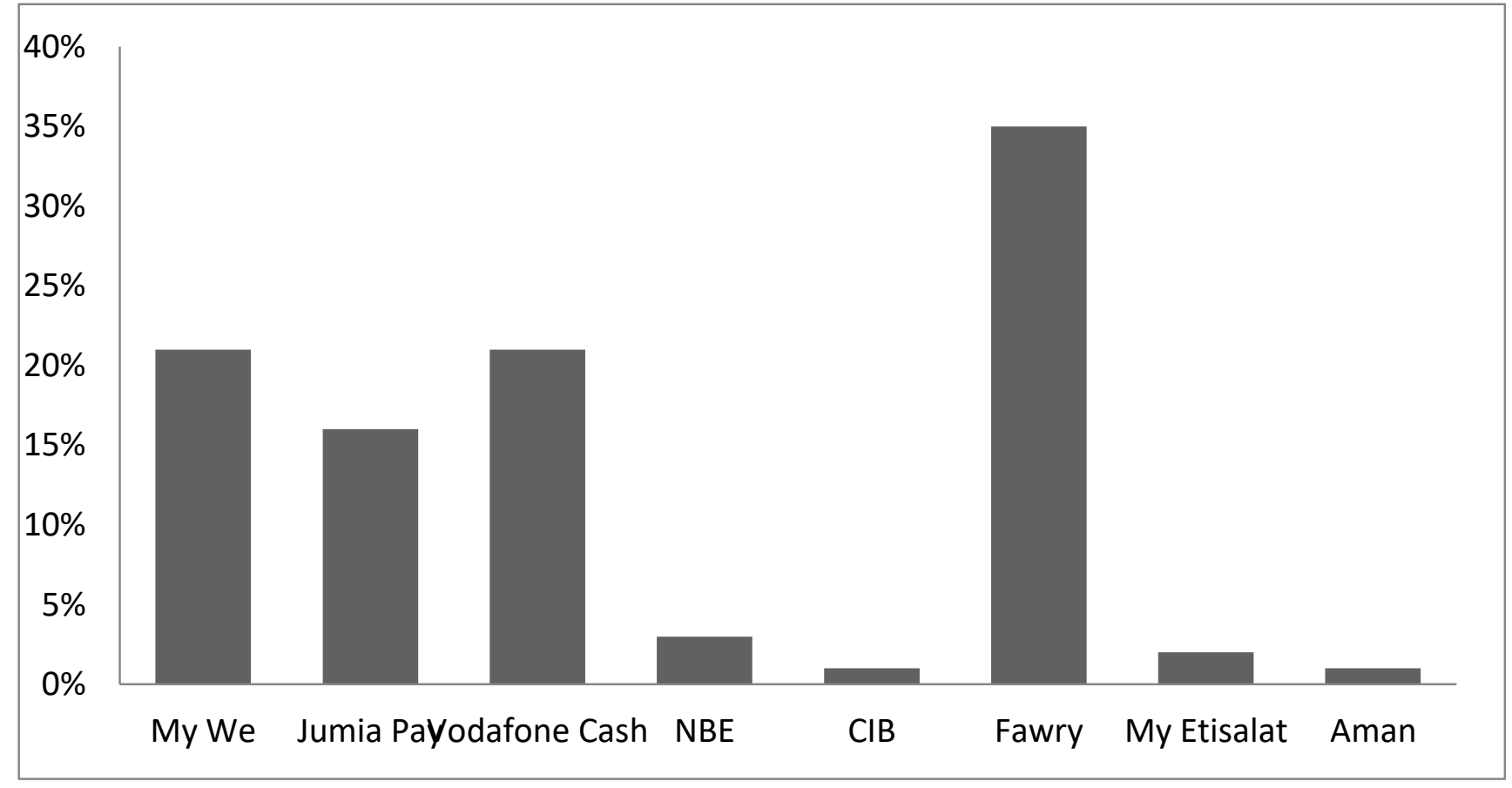

Most of these payment applications would be similar to the SOP proposed framework, which indicates that most respondents would accept the suggested framework. 


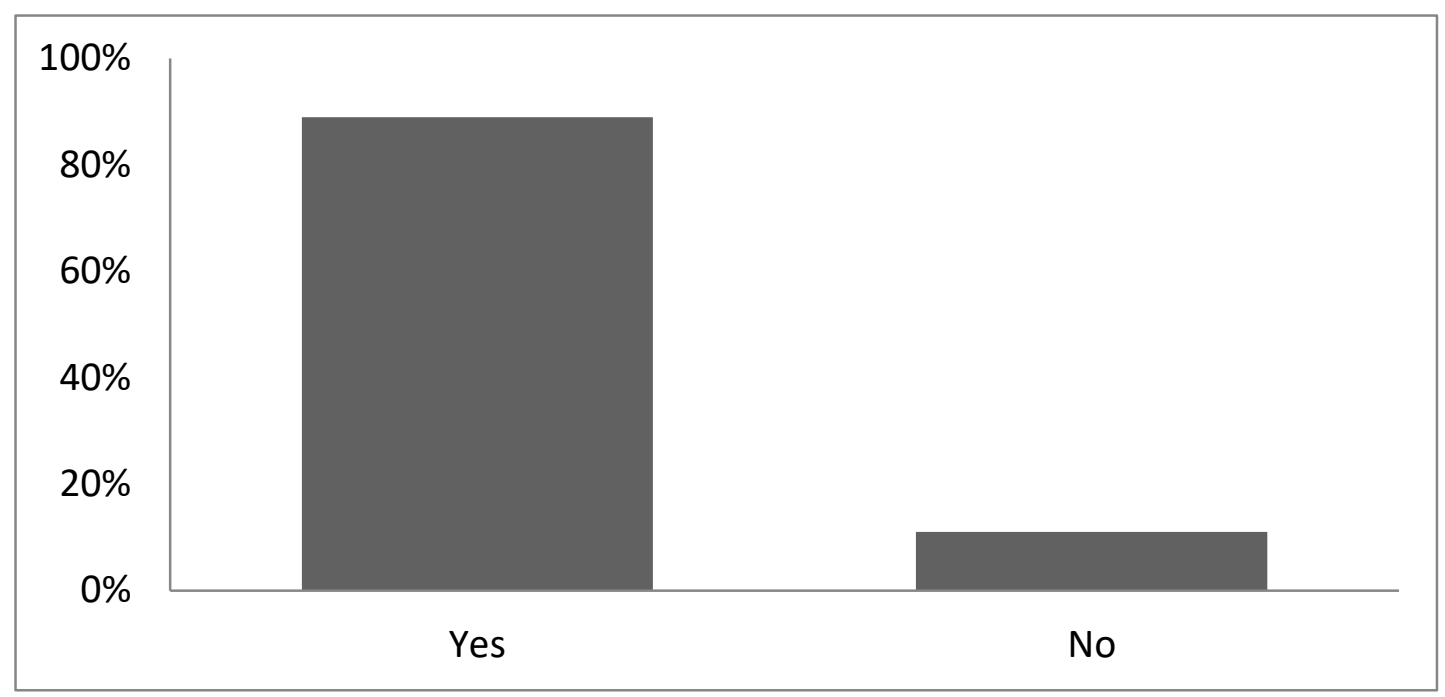

Figure (5) I know about SEKEM Health

89\% knows about SEKEM Health, which indicates that the community respondents would benefit from the SOP Credit points suggested framework.

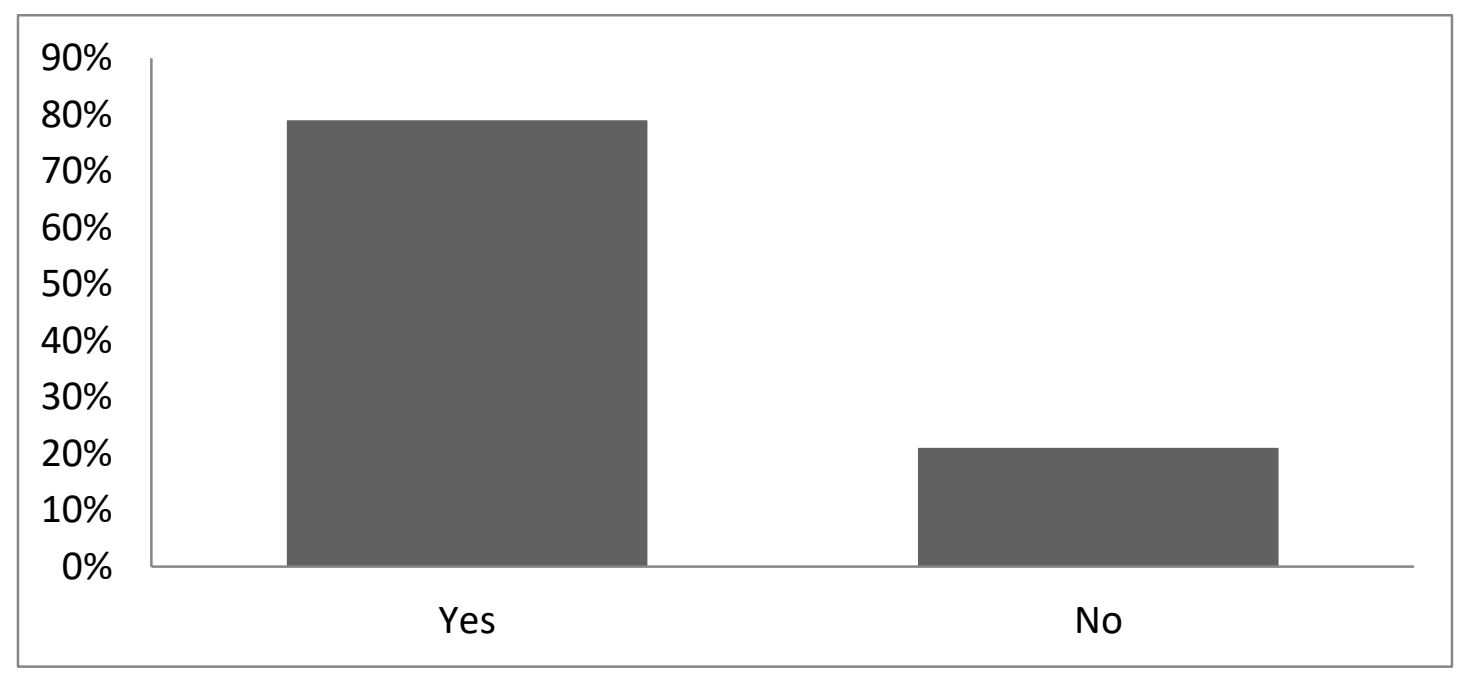

Figure (6) I heard about digital currency before

$79 \%$ knows about digital currency, which indicates that most community respondents are able to accept the SOP innovation in SEKEM Community.

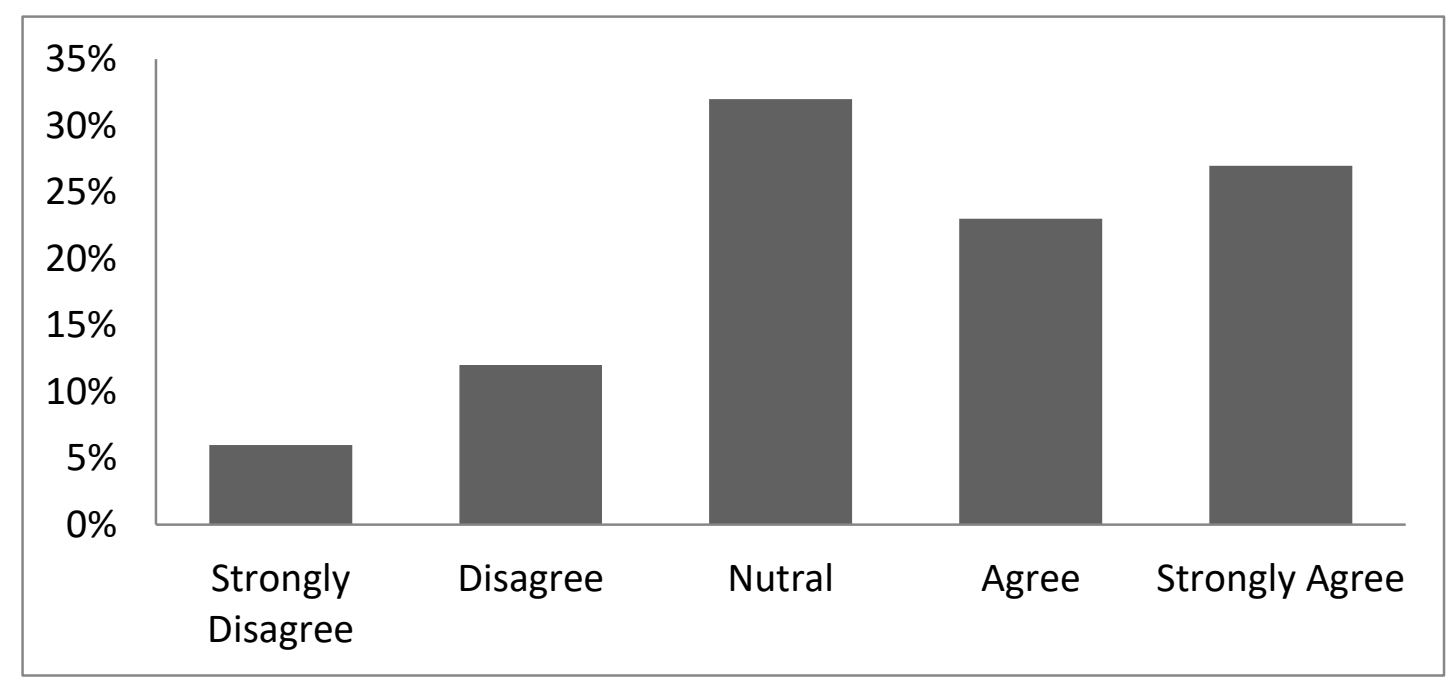

Figure (7) I usually buy ISIS products

Most respondents are buying ISIS products, which indicates that the community respondents would benefit from the SOP Credit points suggested framework. 


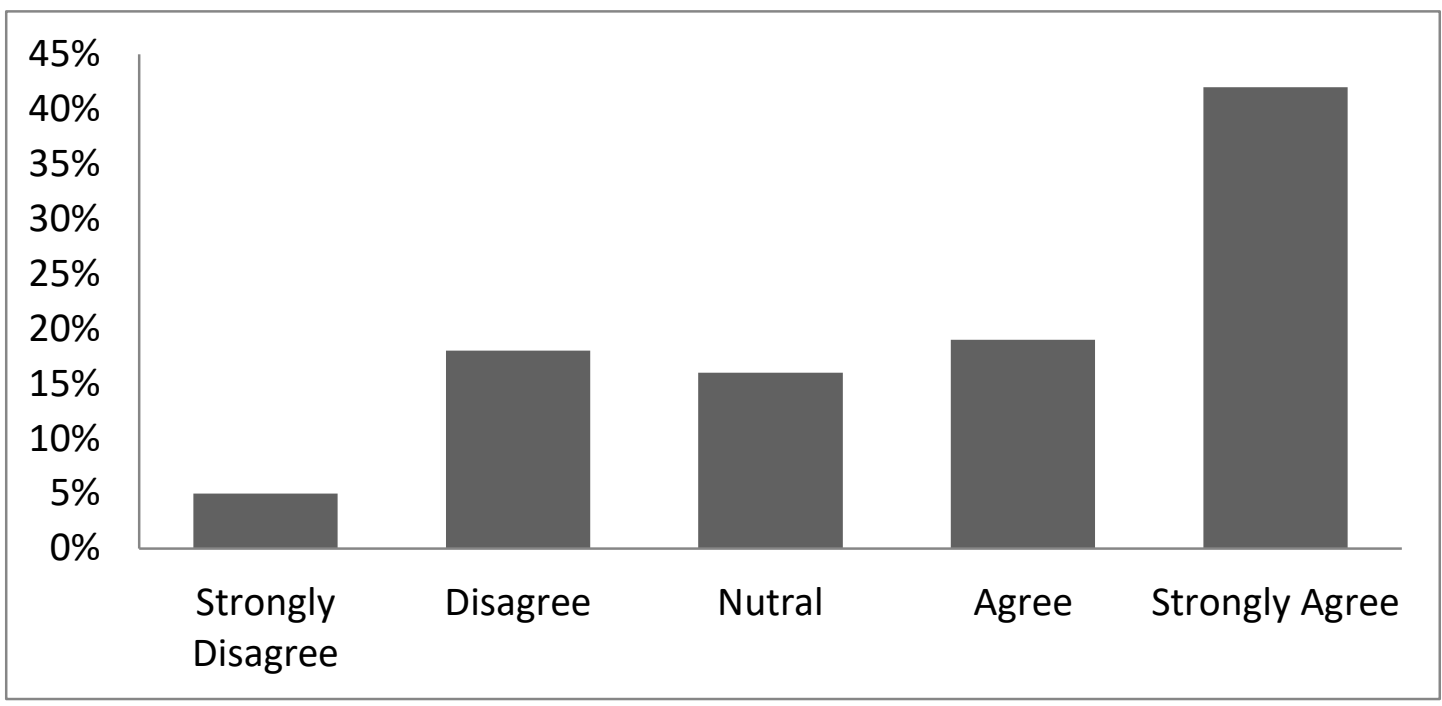

Figure (8) I usually buy from ISI Café (HU Cafeteria)

Most respondents are buying ISI café, which indicates that the community respondents would benefit from the SOP Credit points suggested framework.

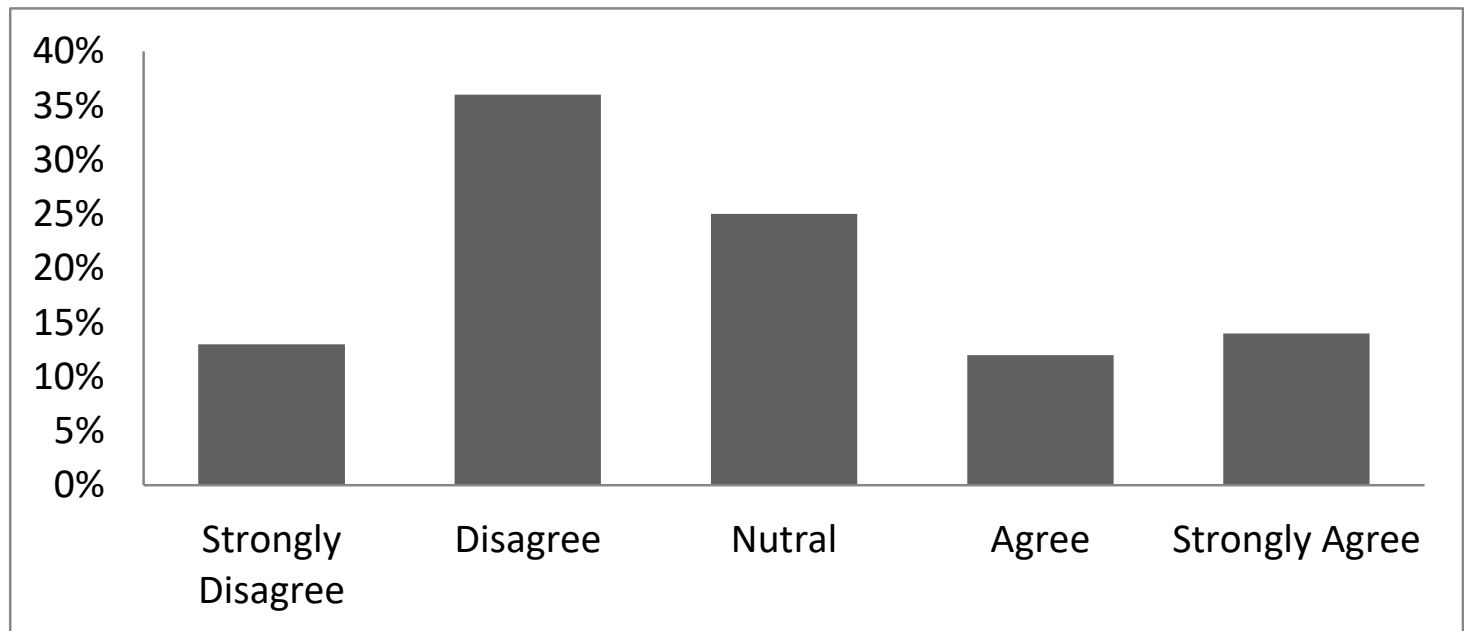

Figure (9) The process of paying the university fees is easy

Most respondents are struggling in paying the university fees, which indicates that the community respondents would benefit from the SOP fast transaction and Credit points suggested framework.

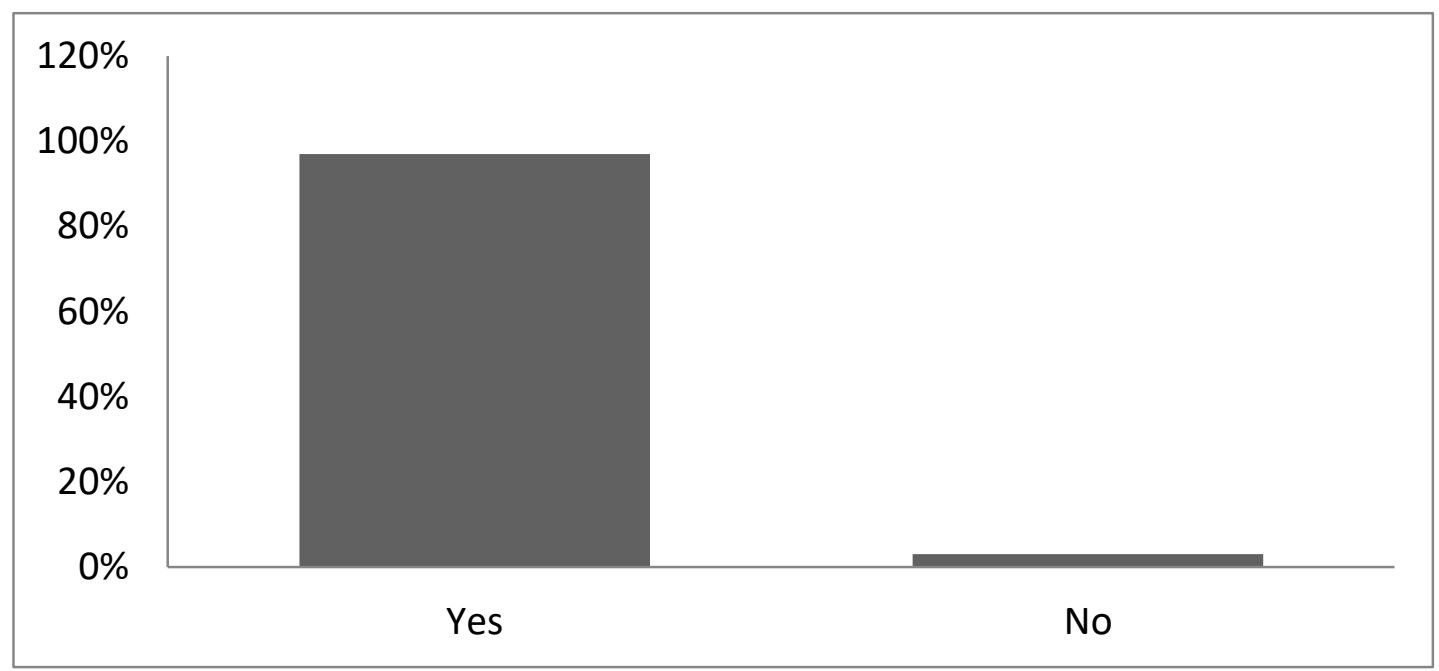

Figure (10) I use SEKEM MIZA

97\% are using SEKEM MIZA, which indicates that the community respondents are already accepting a framework that is very similar to the SOP suggested framework. 


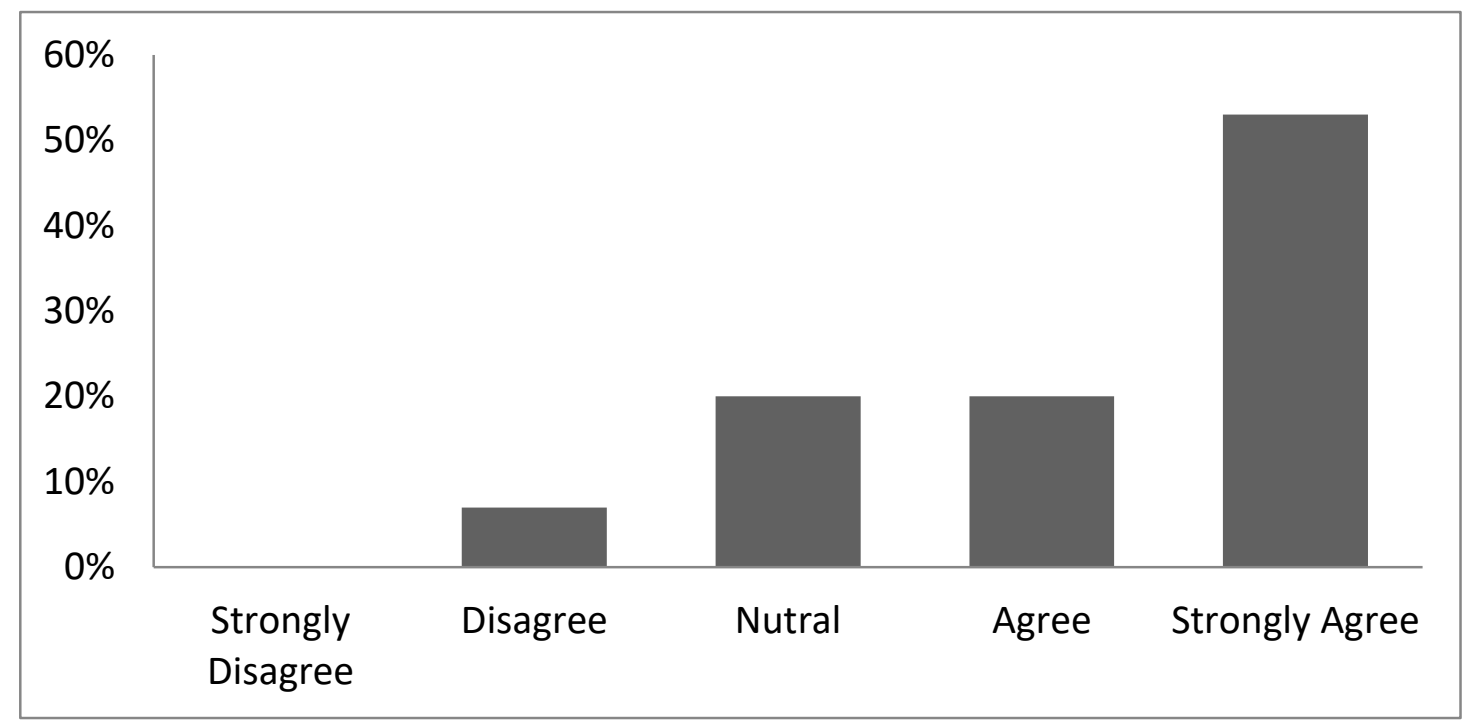

Figure (11) I am satisfied from SEKEM MIZA reward

Most respondents are satisfied from SEKEM MIZA reward, which indicates that the community respondents would benefit from the SOP Credit points suggested framework.

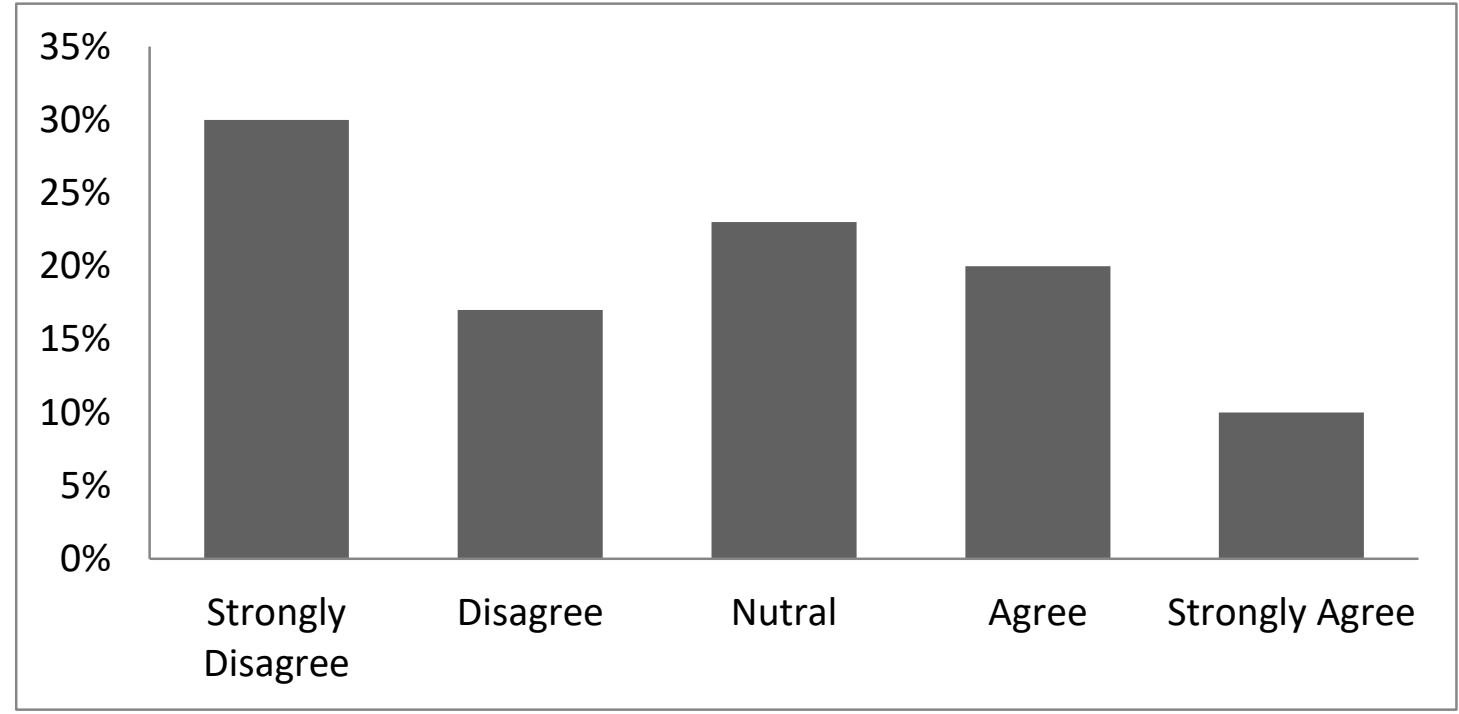

Figure (12) I see difficulty in using SEKEM MIZA application

Most respondents are not facing difficulties while using SEKEM MIZA, which indicates that the community respondents would use the SOP suggested framework without any difficulties.

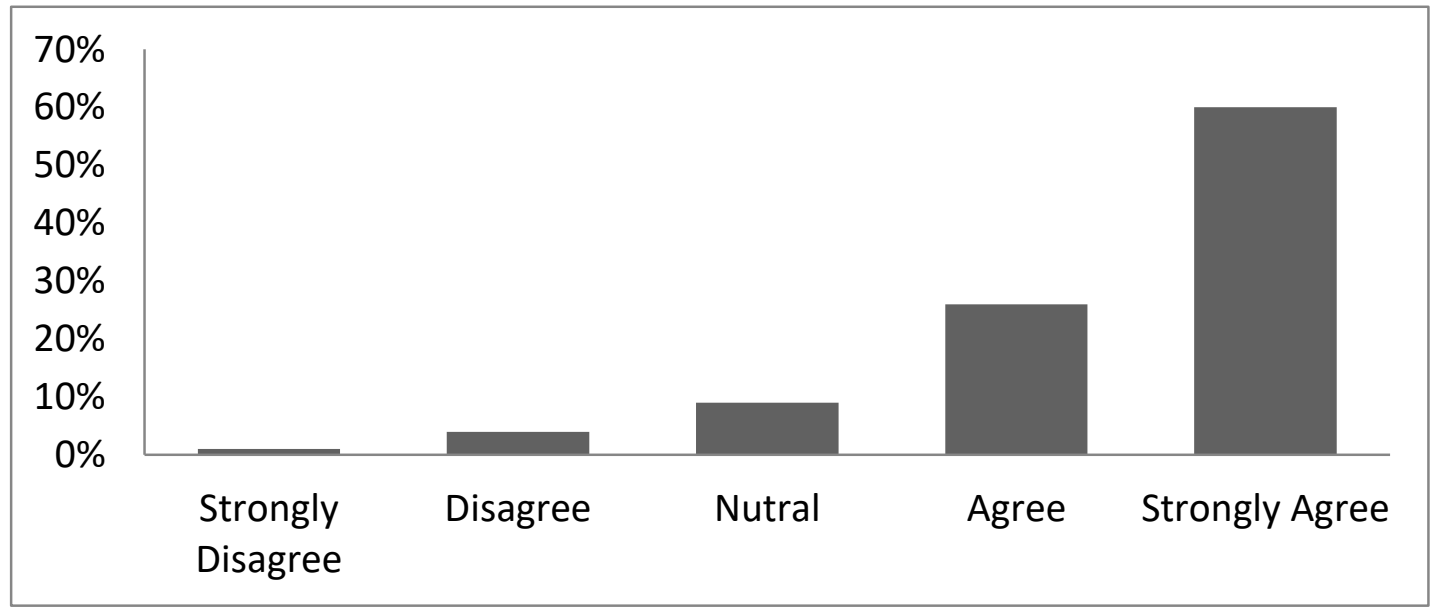

Figure (13) I am satisfied of using digital payment system

Most respondents are satisfied from digital payment system, which indicates that the community respondents would be satisfied from the SOP suggested framework. 


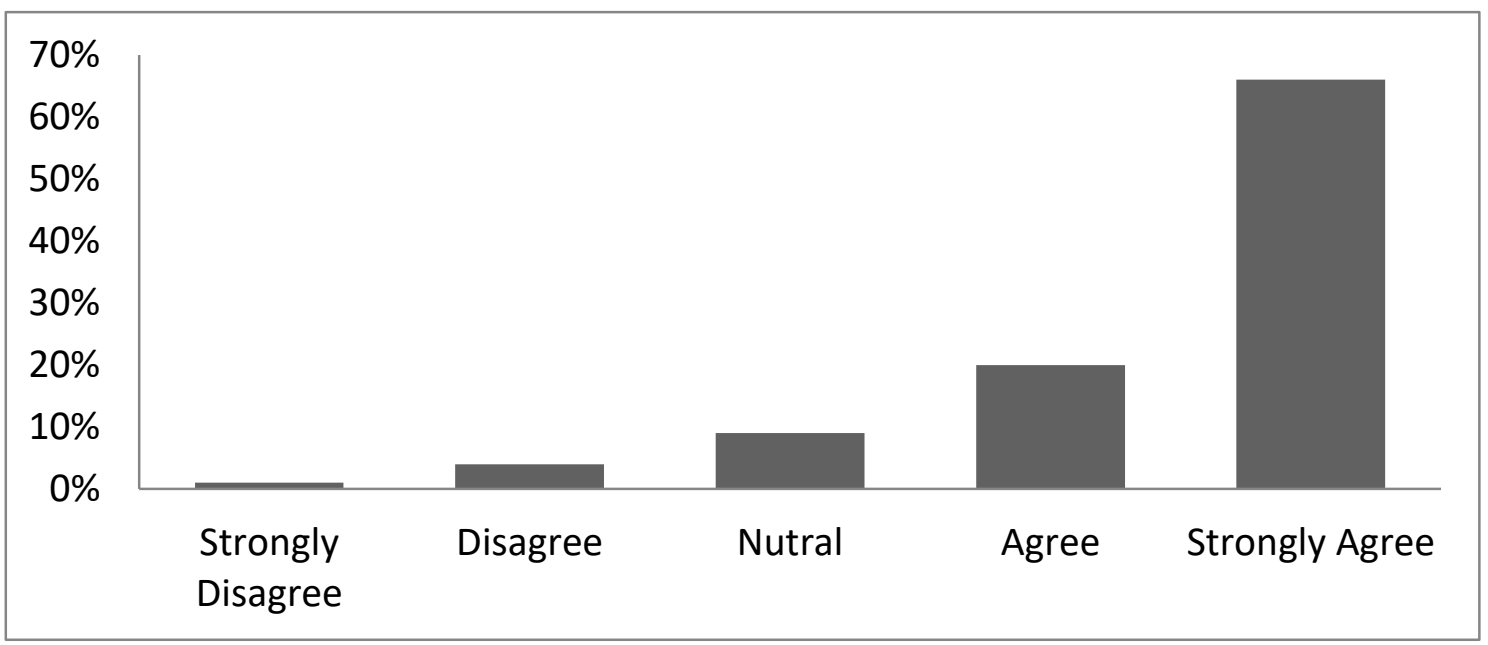

Figure (14) I see that digital payment system is more convenient than the traditional one Most respondents are more into digital payment system, which indicates that the community respondents would accept to convert into the digital SOP system.

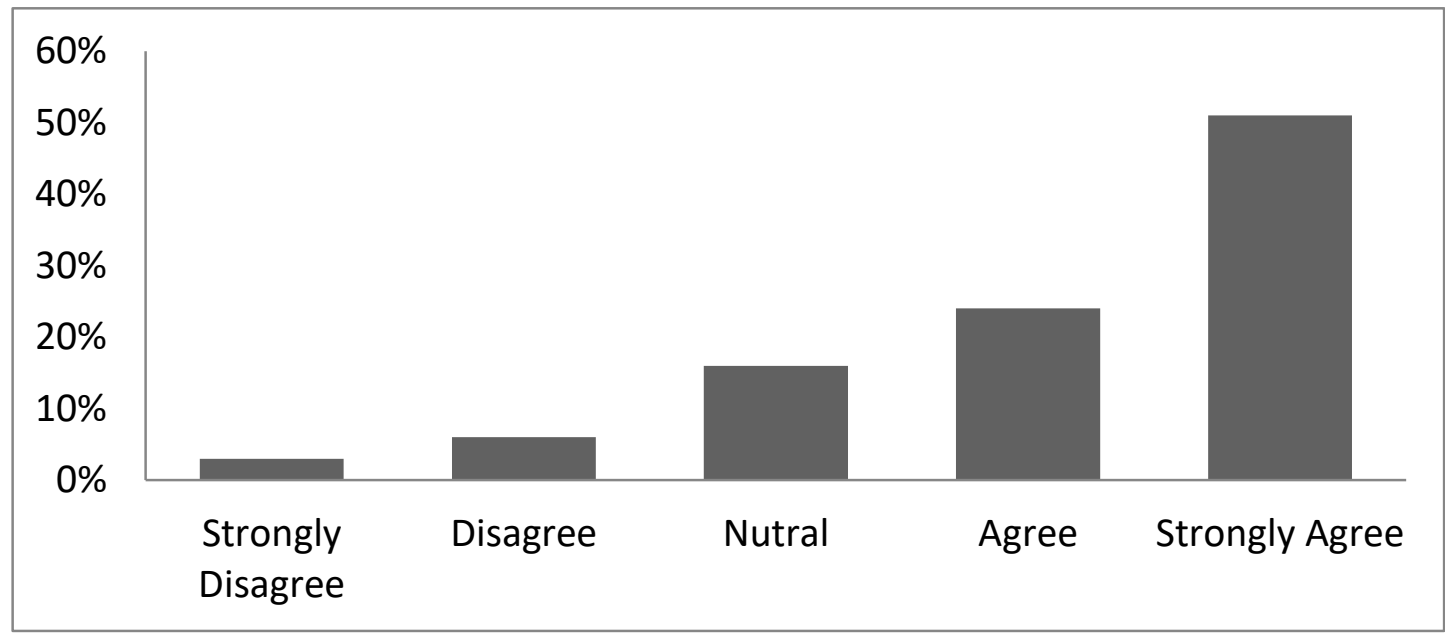

Figure (15) I see that digital payment system is safer than the traditional one

Most respondents are satisfied from digital payment system as it is safe, which indicates that the community respondents would use the SOP suggested framework as it would be safer.

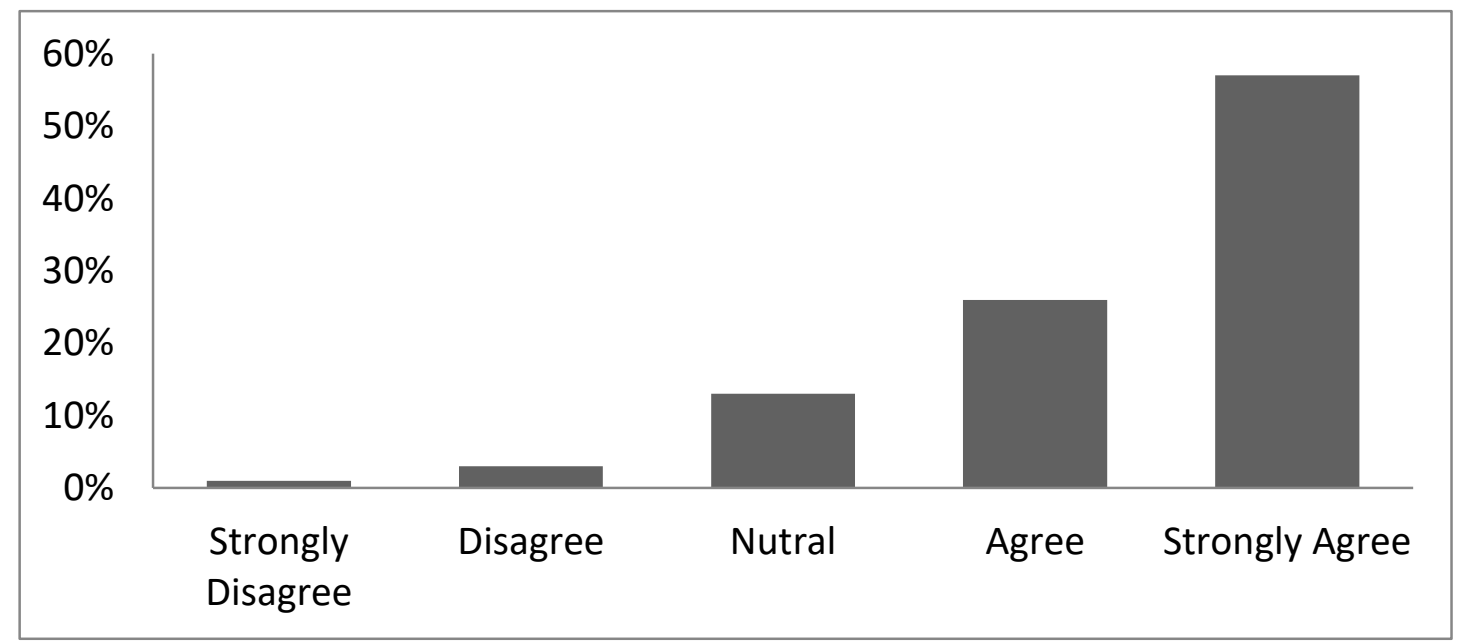

Figure (16) I see that using digital payment system is environmental friendly

$57 \%$ of the total sample is seeing that digital payment system is environmental friendly, which indicates that a financial technology innovation such as developing SEKEM Organic Pound is matching with the sustainable development theme of the SEKEM community.

\subsection{Data Analysis}

The result of the data shows that there is an opportunity of applying digital currency in SEKEM community according to the following main results: 


\section{"The Opportunity of Applying Digital Currency in SEKEM community Egypt"}

- The most challenge of applying digital currency occurs when the user ignore the idea of using a smart phone or does not have a smart phone to make financial transaction, but the survey result was $97 \%$ are using smart phone with $88 \%$ active members on social media and 93\% are already using digital payments applications which for sure are more difficult than the SEKEM Organic Pound application that we are going to develop.

- Also the survey shows that the users of the digital application (students, employees, professors and doctors) are going to accept the idea of the SEKEM Organic pounds points, as $79 \%$ of the total sample has an idea about digital currency, $89 \%$ of the total sample know about SEKEM Health, $27 \%$ of the total sample is always buying ISIS products, $42 \%$ of the total sample usually buy from ISI Café (HU Cafeteria).

- The survey also focuses on the benefits of each SOP user, as for the students $36 \%$ are suffering from the process of paying the university fees, which will be handled by developing SEKEM Organic Pound system which will provide the students with fast and easier payment transactions and also a credit SOP points. As for the employees, doctors, and professors $97 \%$ are using an app called SEKEM MIZA which is also doing the same as SOP but for the staff only. 53\% are satisfied of the SEKEM rewards which act the same as the SOP points, and $30 \%$ are saying that SEKEM MIZA application is easy to use, however that the SEKEM Organic Pound application is going to be developed in easier system than SEKEM MIZA.

- The survey data also shows that $60 \%$ of the total sample is satisfied of using digital payment, which describes how the SEKEM community members will accept such financial innovation. The reasons of making the users satisfied of using digital payment system is that $66 \%$ of the total sample is seeing digital payment system more convenient than the traditional payment system, and due to $51 \%$ of the total sample is seeing digital payment system is more safer than the traditional one.

- Regarding the most important side which is that SEKEM community are always developing innovations that is related to its theme which is the sustainable development, $57 \%$ of the total sample is seeing the digital payment system is environmental friendly, which shows that a financial technology innovation such as developing SEKEM Organic Pound is matching with the sustainable development theme of the SEKEM community.

\section{MANAGERIAL IMPLICATION AND LIMITATION}

This part provide better understand for the possible actions that SEKEM community could start to implement to apply the SOP (SEKEM Organic Pound). The IT department could start to prepare a mobile application system that is related to the proposed idea which is the SEKEM Organic Pound; the application should be designed in three languages which are Arabic, English, and Germany, the SOP rate must be equal to the Egyptian pounds which mean 1 SOP equal 1 EGP. The first step for the user should be creating an account the process of creating such account would be done in two steps. The first step is the personal information data which will require the name, personal ID, data of birth, marital status, and the user role in SEKEM community which can be (Student, Employee, or Doctor). The second step would be the payment method where the user would be required to link a bank account with the application, so they can convert money to SOP. Each user should have a personal code and password to make the payment transaction in a safe way. Also there must be an application in each ISIS stores, ISI Café, Heliopolis University, and SEKEM Health, so they can track the income done by SOP. Regarding the SOP credit points it could be a $1 \%$ of the total transaction which mean if the total transaction is 100 the user will get 1 SOP credit point. An orientation would be needed to train and introduce the idea to the users. Due to the global pandemic (Covid-19) I was not able to make a large numbers of interviews with experts and SEKEM decision makers, and also due to the small frame of time as this is a research prepared as my graduation thesis, I had to stick to the descriptive research type in order to have the ability to comply with the given deadline, so other experimental research would be needed to support the implementation of the proposed idea of the SEKEM Organic Pound, as the central bank of Egypt may have a role of supporting the SOP in the future.

\section{RECOMMENDATION}

As for the recommendation part it would be beneficial for the SEKEM community if they managed to split the topic of this research into three working sides, each one of the three sides should have the main focus on implementing the SEKEM Organic Pound the first side could work on the preparation of the online mobile payment application, the second side could work on the cost needed to implement such application, the third side would be experimental research to support the proposed idea of the SEKEM Organic Pounds and found sources of fund to support in the cost of the SOP preparation. These three sides mainly to implement the best possible digital currency that are more into reducing the living cost of the SEKEM community. After conducting these three sides, the SEKEM community will have the opportunity to apply the digital currency in the most sustainable way. 


\section{CONCLUSION}

This paper has reviewed the scientific published papers by many different authors in many years on digital currency definitions, and in particular, it has examined the implications of each type of digital currency. All these scientific published papers led to form a clear understanding of what is digital currency in definition and what are the most known types of digital currency. After the digital currency was clearly described, the virtual crypto currency was the best type to be applied in SEKEM Community, so other published scientific papers were needed to describe practically virtual crypto currency and this was done by taking the most successful virtual crypto currency which is the Bitcoin, to explore how the Bitcoin started and how it works. As SEKEM community is located in Egypt which is one of the most important Arabic Islamic countries, the Islamic prospective regarding the implementation of digital currency was needed, so other scientific published papers were used to get the Islamic prospective on digital currency. While focusing on most successful virtual crypto currencies, I have found that the topic digital currency includes some criminal risks, so it was important to explore the risks of applying digital currency. After deciding the virtual crypto currency type, I started creating a proposed frame work that is applicable to SEKEM community which is SEKEM Organic Pound, but this step was followed by a survey on a convenient sample of Heliopolis University to describe the opportunity of applying digital currency. The last steps were analyzing the data of the survey to get useful information regarding applying digital currency, discussing the managerial implication and limitation, and giving recommendation toward applying digital currency in SEKEM community.

The result of this research was that the proposed circuit by using digital currency could be applied in SEKEM community and utilizing digital currency could lower some of living cost of SEKEM community members, but for sure other experimental research would be needed to support the implementation of the proposed idea of the SEKEM Organic Pound, as the central bank of Egypt may have a role of supporting the SOP in the future.

\section{REFERENCES}

1. Aytaç Altan, Seçkin Karasu, Stelios Bekiros. (2019, July 19). Digital currency forecasting with chaotic meta-heuristic bio-inspired signal processing techniques. Retrieved May 13, 2021, from Science Direct:

https:/www.sciencedirect.com/science/article/abs/ pii/S0960077919302632

2. Böhme, Christin, Edelman, and Moore. (2015). "Bitcoin: economics, technology, and governance". The Journal of Economic Perspectives , 213-238.

3. Briere, M., Oosterlinck, K., \& Szafarz, A. (2013, April 25). Virtual Currency. Retrieved May 18, 2021, from Tangible Return: https://link.springer.com/article/10.1057/jam.2015. 5

4. Bryans, D. (2014). "Bitcoin and money laundering: mining for an effective solution". Indiana Law , 44.

5. CBE. (2019, December). Highlights of The Central Bank of Egypt's FinTech and Innovation Strategy. Retrieved May 14, 2021, from The Central Bank of Egypt's: https://fintech.cbe.org.eg/home/index?en

6. Chen, Pandey . (2014). The value of Bitcoin in enhancing the efficiency of an investor's portfolio. Journal of financial planning , 44-52.

7. FATF. (2014). Virtual Currency Key Definitions and Potential AML/CFT Risks. Paris: FATF.

8. Francisco Javier García-Corral, J. d.-V.-G.-G. (2020, July 15). Complementary Currencies: An Analysis of the Creation Process Based on Sustainable Local Development Principles. Retrieved May 14, 2021, from https://www.mdpi.com/2071-1050/12/14/5672/pdf

9. Groysman, I. 2. (2018, June 25). Revolution in crime: How cryptocurrencies have changed the criminal landscape. Retrieved May 13, 2021, from https://academicworks.cuny.edu/cgi/viewcontent.cg $\mathrm{i}$ ? article $=1088 \&$ context $=\mathrm{jj} \_$etds

10. Hossain, M. S. (2021, January 12). What do we know about cryptocurrency? Past, present, future. Retrieved May 22, 2021, from China Finance Review International: https://www.emerald.com/insight/content/doi/10.11 08/CFRI-03-2020-0026/full/html

11. Houben, R., \& Snyers, A. (2018, June 25). Cryptocurrencies and blockchain. Retrieved April 23, 2021, from European Parliament:

https://blog.elitex.ir/wp-

content/uploads/2020/06/Cryptocurrencies-and-

Blockchain.pdf

12. Ibrahim Bassam Zubaidi,Adam Abdullah. (2017, September). Developing a Digital Currency from an Islamic Perspective: Case of Blockchain Technology. Retrieved May 1, 2021, from

https://www.researchgate.net/publication/32010935 8_Developing_a_Digital_Currency_from_an_Islam ic_Perspective_Case_of_Blockchain_Technology

13. J.W.Biggs. (2018, May 5). Introduction to Digital Currency. Retrieved April 30, 2021, from Bookdown:

https://bookdown.org/Jack_Biggs/Cryptocurrency/

14. Jian, K. (2020, December 8). Energy Coin: A Universal Digital Currency Based on Free Energy. Retrieved May 18, 2021, from American Journal of Modern Energy:

http://article.ajome.org/pdf/10.11648.j.ajme.20200 605.11.pdf

15. JianiWu, Nguyen Khoi Tran. (2018, August 28). Application of blockchain technology in sustainable 


\section{"The Opportunity of Applying Digital Currency in SEKEM community Egypt"}

energy systems: An overview. Retrieved April 15, 2021, from Sustainability: https://www.mdpi.com/2071-1050/10/9/3067/pdf

16. Kaplanov, N. (2012, November 1). Nerdy money: Bitcoin, the private digital currency, and the case against its regulation. Retrieved May 23, 2021, from

http://lawecommons.luc.edu/cgi/viewcontent.cgi?ar ticle $=1920 \&$ context $=\mathrm{lclr}$

17. Michel, A. \&. (2015). Community currencies and sustainable development: A systematic review. Retrieved May 15, 2020, from Ecological economics:

https://www.researchgate.net/profile/Marek_Hudon /publication/277338066_Community_currencies_a nd_sustainable_development_A_systematic_revie w/links/5c49ba91a6fdccd6b5c54997/Communitycurrencies-and-sustainable-development-Asystematic-review.pdf

18. Omar, M. N. (2011). The Islamic view on money and its implication for financial instruments. ISRA International Journal of Islamic Finance , 161-167.

19. Rosenbaum, H. S. (2020, February 18). Toward understanding FinTech and its industry. Retrieved May 19, 2021, from Managerial Finance: https://blogs.mtu.edu/computing/files/2020/01/Tow ard-Understanding-FinTech-and-its-Industry01162020-AOF.pdf

20. Ryu, H.-S. (2018, January 16). Understanding Benefit and Risk Framework of Fintech Adoption:Comparison of Early Adopters and Late Adopters. Retrieved April 19, 2021, from https://scholarspace.manoa.hawaii.edu/bitstream/10 125/50374/1/paper0487.pdf

21. Scott Gilbert, Hio Loi. (2018, January 10). "Digital currency risk.". Retrieved May 10, 2021, from International Journal of Economics and Finance: https://pdfs.semanticscholar.org/628e/3a8db25f72d 1352903634023a6013f148112.pdf

22. Shah, M. (2017, October). Digital Currency: The Future of Money. Retrieved April 30, 2021, from International Journal on Recent and Innovation Trends in Computing and Communication: https://d1wqtxts1 xzle7.cloudfront.net/56815298/15 09774422_04-11-

2017.pdf?1529311767=\&response-content-

disposition=inline\%3B+filename\%3DDigital_Curr ency_The_Future_of_Money.pdf\&Expires $=161982$ 5948\&Signature $=$ SJ cvVN5ZCELaUMziwQYirb0 i-xxOw7CXC6WOdzkmhnLwNDP61

23. Shoaib, M., Ilyas, M., \& Khiyal, M. S. H. (2013). Official digital currency. Eighth International Conference on Digital Information Management .

24. Singhal, A., \& Rafiuddin, A. (2014, June 25). Role of bitcoin on economy. Retrieved May 1, 2021, from https://d1wqtxts1xzle7.cloudfront.net/55986475/W CECS2014_pp1028-

1033.pdf?1520404280 $=$ \&response-content disposition=inline $\% 3 \mathrm{~B}+$ filename $\% 3 \mathrm{DWCECS} 201$ 4_pp1028.pdf\&Expires $=1619909357 \&$ Signature $=\mathrm{a}$ AI4khwrO8wD4FujXnDdWXvyUvaGaPu1H4gzR F7-7bYYG15kLncvf BJwT6w9cIZESNDWs

25. Valery Titov, M. U. (2021, March 19). Cryptocurrency Open Innovation Payment System: Comparative Analysis of Existing Cryptocurrencies. Retrieved April 26, 2021, from Journal of Open Innovation: Technology, Market, and Complexity: https://www.mdpi.com/2199-8531/7/1/102/pdf

26. $\mathrm{Xu}, \mathrm{Y}$. (2020, July 14). ADOPTION OF CRYPTOCURRENCY IN EUROPE . Retrieved April 16, 2021, from Savii Digital Marketing Agency, England :

https://www.theseus.fi/bitstream/handle/10024/493

246/Xu\%20Yuchen.pdf?sequence=2 